\title{
Pulp Dressing Agents Used in Primary Teeth: A Review of the Literature
}

\author{
Filareti-Efthymia Boulioni and Aristidis Arhakis
}

\section{ABSTRACT}

Background: Pulpotomy is a technique of vital pulp therapy which can be performed in a primary tooth with pulp exposure due to caries or trauma when there is no clinical or radiographic sign of irreversible pulpitis or necrosis. Since today many different medicaments and techniques have been researched as pulpotomy agents and studies have shown the effectiveness but also the limitations of them.

Aim: The aim of this literature review is to overview the medicaments which were used in the past for pulpotomy in primary teeth, but also to evaluate the techniques and medicaments from the present and the future.

Results: Formocresol was the first-choice material for many decades, but its use has been limited due to potential mutogenetic and carcinogenetic effects in humans. In addition, glutaraldehyde is no longer used as a material for pulpotomy due to its toxicity. Mineral trioxide aggregate (MTA) seems to have better or comparable success rates as the old gold standard formocresol, while other materials have high effectiveness. Calcium hydroxide was related to lower success rate and due to adverse effects as the internal root resorption is no longer recommended. Electrosurgery and laser are alternative techniques, while collagen and enamel matrix derivative (EMD) have been researched the last years and also studies about the bone morphogenetic proteins (BMPs) presented promising results. Also, other medicaments, which have been evaluated as pulp dressing materials, are included in this review and they seem to lead to acceptable results.

Conclusions: MTA seems to be the new gold-standard for pulpotomy, while also other medicaments as ferric sulfate, sodium hypochloride, Portland cement, Biodentine can lead to comparable results. Electrosurgery and laser pulpotomy are alternative and non-pharmacological techniques with good success rates, while also other alternative materials seem to have promising results, but further research is needed.

Keywords: Medicaments, primary teeth, pulpotomy.

\section{INTRODUCTION}

According to the Global Burden of Disease Study, tooth decay is the most common oral disease in permanent dentition, but it is also highly related to primary teeth with more than 530 million children worldwide suffering from dental caries [1]. Despite the progress in the field of the prevention of dental caries and the decrease of the prevalence and severity of dental caries lesions among 5- and 12-years old, a huge part of the world still suffers from this disease [2].

Untreated caries is one of the possible causes of pulp exposure which was traditionally treated with root canal therapy. However today, the management strategies of exposed pulp aim to the limitation of pulpectomy and the selection of the vital pulp techniques such as pulpotomy as the treatment of choice [3].

According to American Association of Pediatric Dentistry [4], pulpotomy is defined as the surgical removal of the coronal vital pulp tissue followed by placement of a
Published Online: January 24, 2022

ISSN: $2684-4443$

DOI : $10.24018 /$ ejdent.2022.3.1.138

\section{F. Boulioni*}

School of Dentistry, Aristotle University of Thessaloniki, Greece.

(e-mail: filaretimp@gmail.com)

A. Arhakis

Department of Pediatric Dentistry, School of Dentistry, Aristotle University of Thessaloniki, Greece. (e-mail: arhakis@dent.auth.gr)

*Corresponding Author biologically acceptable material in the pulp chamber and restoration of the tooth. Specific indications are considered to play a significant role for the success of this pulp therapy such as the presence of normal or reversible pulp tissue with pulp exposure due to caries or trauma with no radiographic signs of infection or pathologic resorption [2]. The aim of pulpotomy is to preserve the radicular pulp, avoiding pain and swelling and also to retain the tooth preserving the arch integrity while the remaining pulp tissue is vital without suppuration, purulence, necrosis, or uncontrolled hemorrhage [4], [5]. Key factors for the success of this pulp tissue treatment are among others the right diagnosis, the condition or/and the grade of the inflammation of the pulp, a final restoration which prevent the microleakage and the understanding of the physiological pulp response to the capping [3]. Furthermore, another key for the success of this treatment option is the selection of a suitable technique and medicament as pulp capping material. An ideal pulpotomy agent must have specific properties such as biocompatibility, 
antibacterial activity, property to seal the remaining pulp tissue and not being resorbable. Also, it should promote the healing of the pulp, be harmless and not interfere the physiological root resorption [6]-[8]. Buckley's formocresol was first introduced as a pulpotomy medicament in 1904 and since 1930 was considered to be the gold standard material for this pulp tissue therapy [9], [10]. Although, over the years many techniques and materials have been developed as alternatives to formocresol and the main purpose of this literature review is to compare and evaluate these different procedures and medicaments based on the clinical, radiographical or/and histological results of the following studies.

\section{Pulp Dressing Materials}

\section{A. Formocresol}

Formocresol was at first consisted of equal parts of formalin and tricresol intended to fix nonvital pulp tissue [11]. Over the years this composition changed, which led to the so-called «Buckley's formula» with 19\% formaldehyde, $35 \%$ creosol, glycerin, and water [12]. Formocresol has not the ability to promote dental bridge formation or odontogenesis, but its use aims to the devitalization of the dental pulp in teeth with deep caries [12]. It was characterized for many years as the "gold standard" medicament for pulpotomy in primary teeth with high clinical and radiographical success rates which were according to clinical studies between 73-98\% [13]-[16]. Reference [13] showed that the clinical and radiographical success rate of formocresol was at 12-months follow-up 73.3\% and they found some side effects of this medicament such as internal root resorption in the $6.3 \%$ of the treated primary teeth, external root resorption and furcation radiolucency in $20 \%$. Reference [14] came to the result that pulpotomy with formocresol had $96 \%$ radiographic success rate after 12 months and. [15] showed $98.1 \%$ success rate after the same time period, with pulp canal obliteration as the most common radiographic observation due to the high odontoblastic activity as a proof of pulpal vitality. Also, according to the clinical study of [16], the radiographic success rate was significant different than the previous results (90\%) and it was also important that the patients had no clinical signs of failure. Worth mentioning is also the histological evaluation after the use of formocresol as a capping material in a pulpotomy which showed that this material causes more times than others severe inflammation and sometimes necrosis maybe due to its property to devitalize the pulp tissue [17].

However, the last years serious concerns have been developed about the safety of formocresol as a used medicament in children due to formaldehyde. Formaldehyde has been associated with carcinogenesis, mutagenicity [18], [19], cytotoxicity and immune sensitization and it can cause 3 most common types of damages in DNA: sister chromatid exchanges, micronuclei and chromosomal aberrations and deletions [20], which have been found in peripheric lymphocytes of human exposed to formaldehyde [21]. However, this seems to occur only the site of the exposure, while also the evidence for the distant sites is not sufficient.
In addition, it had been proven that formaldehyde can be systematically distributed after a pulpotomy procedure and animal studies have shown the systematically absorption of this substance in rats and dogs [20], but also another animal studies from [22], showed the relation between formaldehyde and development of squamous cell carcinoma in rats. In 2004, the International Agency for Research of Cancer classified formaldehyde as a carcinogenic in human beings, when there was sufficient evidence that it can cause nasopharyngeal cancer and strongly proof that it can provoke leukemia in humans, although the evidence about the relation between nasal/paranasal sinus carcinoma and formaldehyde is still limited [23]. On the other hand, dental studies led to different conclusions, and they support that the use of formocresol in pulpotomy is not mutagenic based on the result that chromosomal aberrations were found only in $5 \%$ of the patients after pulpotomy with this medicament [18]. According to [24] and [25], formaldehyde cannot also lead to genotoxicity and [19] showed that formocresol is not mutagenic maybe because the dose in case of a use as a pulpotomy material is not enough to provoke DNA damage.

\section{B. Glutaraldehyde}

Glutaraldehyde was introduced as a pulpotomy medicament from Gravenmade who suggested that this dialdehyde had better fixative properties and it can less diffuse the periapical tissues than the gold standard-formocresol. After the use of glutaraldehyde a homogenous eosinophilic zone is produced so the remaining pulp can keep its vitality [26]. According to [27] the success rate of glutaraldehyde is $82 \%$ at 25 -months follow-up and worth mentioning is that based on other clinical studies the most common radiographic signs of failure of a pulpotomy treatment with glutaraldehyde are periodontal ligament widening (PDL), internal root resorption, furcation, and periapical radiolucency [28]. Also, clinical parameters play a significant role with pain, mobility and sinus formation the most common symptoms [28]. Reference [29] have also evaluated four different concentrations and types of glutaraldehyde and the results of the clinical study showed that there was no significant difference in the success rates between them. In addition, the main concern about glutaraldehyde is its relation to toxicity and mutagenicity which have been proved to be similar to formocresol [26] and combined with the lower success rates in comparison with formocresol, it is now longer considered as a material of choice for pulpotomy procedures [12].

\section{Calcium Hydroxide}

Calcium hydroxide $(\mathrm{CH})$ is a crystal or white inorganic compound and regarding its mechanism of action it can lead to necrosis of the tissue surface, which can then passively calcify [30], is characterized from its high pH alkalinity [31] and its property to create a layer of hard tissue at the orifice which can promote pulp healing [32]. It is biocompatible with the ability to stimulate dentin formation and it also shows good antimicrobial properties. It has been proved that $\mathrm{CH}$ is efficient against microbes such as A. viscosus and L. acidophilus due to its high alkaline $\mathrm{pH}$ and the fact that these microbes can live in environment with lower $\mathrm{pH}$ [7]. According to studies, its success rates as pulpotomy material are significant lower that other used medicaments with only $64 \%$ success after 12 months follow-up [33]. Also, [34] 
compared the efficacy of mineral trioxide aggregate (MTA) and $\mathrm{CH}$ when they performed pulpotomy in 34 primary molars in total and they revealed that the success rate of the $\mathrm{CH}$ group was $64.7 \%$ with internal root resorption the most frequent sign of failure. Reference [35] presented also in their clinical trial in 139 pulpotomised primary molars in total that the $\mathrm{CH}$ group had at 24 months follow up $77 \%$ and $45 \%$ clinical and radiographic success rates respectively, which were significantly lower than the rates of the other two MTA groups of the same trial. Reference [14] showed that the total success rate after 12 months is $86 \%$ but at the 24 months follow-up this rate dropped to $53 \%$. Reference [32] also found that $\mathrm{CH}$ is related to clinical and radiographical signs such as pain, swelling, widening of the periodontal ligament and root resorption. Another clinical study also presented that internal and external root resorption is more frequent when $\mathrm{CH}$ was used as a pulpotomy material [14] and its cause may be the possible tunnels in the dentine bridge which can be the cause also for pulp irritation and finally the loss of the tooth [36] and that is the cause for the strong limitation of its use nowadays. However, calcium-enriched mixture cement has recently introduced which seems to lead to promising results. It can promote the dentinal bridge formation and by this way to help the remaining pulp tissue to maintain its vitality [37].

\section{Ferric Sulfate}

Ferric sulfate (FS) is a non-aldehyde coagulative agent [38], which was at first used as a pulpotomy material due to its haemostatic properties [39]. The mechanism of its action has been researched and it has been shown that it can form a barrier from a ferric-ion protein clot when it comes in contact with blood at the surface of the pulp and by this way the pulp tissue can maintain its vitality [40]. Clinical studies showed that FS is as successful as a pulpotomy agent as FC. The success rate after 20 months is $97.2 \%$ as the failure rate was $2.8 \%$ due to radiographic signs of internal root resorption without any clinical symptoms [41]. Almost the same promising results were presented also in other studies, where the radiographic success rate of FS was $96.7 \%$ without any clinical failure and the difference from other materials such as MTA was insignificant [42]. In addition, in another study which compared FS to two non-pharmaceutical pulpotomy techniques, it was presented that at the 9months follow-up the clinical success of FS was $86.6 \%$, whereas the radiographic success rate was $80 \%$ with the internal resorption as the most frequent failure sign [43]. Furthermore, [44] compared FS to Biodentine and MTA and the results of the clinical trial showed that the success rate of FS at 12 months follow up was $82.75 \%$ and the difference between the above materials was statistically insignificant. Reference [45] performed in a total of 30 primary molars pulpotomy with FS, electrosurgery and laser in order to compare these three techniques and the results showed that at 12 months follow up the FS group had $80 \%$ clinical and radiographic success rate. Reference [46] also performed pulpotomy in 81 primary molars with FS, sodium hypochlorite and formocresol and they performed clinical and radiographic evaluation every month in a follow up period of 18 months. The results showed that at the last follow up FS had $87 \%$ clinical and $95.7 \%$ radiographic success rate and the difference was insignificant in comparison with the old gold standard. Also, according to
[47] the clinical success rate of FS as a pulpotomy agent in 15 primary molars at 24 months follow up was $100 \%$ and the overall radiographic success rate was $87 \%$. Another clinical trial from [48] also showed that FS led to great results with $100 \%$ radiographic success rate at 12 months follow up without any clinical symptoms, although this rate dropped to $85,7 \% 18$ months after the pulpotomy. Reference [49] selected 71 primary molars with deep carious lesions, they performed pulpotomy with FS and they found that the overall success rate at 24 months follow up was $91.5 \%$. Reference [50] divided 102 primary molars in two groups and they performed in the group of 79 teeth pulpotomy with FS and the results showed that the clinical and radiographic success rates of this group were $84 \%$ and $70 \%$ respectively. Also, worth mentioning is the pulpal response to the use of the FS as a pulpotomy agent from a histological sight. Regarding the production of reparative dentine, a dental bridge is present in almost all cases which covers or trying to bridge the site of the pulp exposure. FS can provoke also moderate inflammation of the pulp tissue and mild infiltration of macrophages and giant cells which was related to possibility of healing of the remaining pulp [40]. According to the results above, FS is suitable as a pulpotomy agent, and it can lead to comparable results to the old standard-formocresol.

\section{E. Mineral Trioxide Aggregate}

Mineral trioxide aggregate (MTA) was introduced early 1990s and it was approved for human usage from FDA in 1998 [36]. It consists of a fine hydrophilic powder [48], it has an initial alkaline $\mathrm{pH}$ of 10.2 which during its settings reaches a $\mathrm{pH}$ of 12.5 and its main substances are calcium phosphate and calcium oxide [7]. It is a very biocompatible and bioactive material with good sealing abilities, and it also presents the property to promote regeneration when it comes in contact with the pulp tissue [36]. The mechanism of its action has been researched and it is now known that it is related to the hydration reaction and although MTA does not contain $\mathrm{CH}$, it produces a calcium silicate hydrate with dissociates in $\mathrm{CH}$ molecules and the result is $\mathrm{CH}$ with a silicate matrix. Regarding its antimicrobial activity it has been presented that it is less efficient against $\mathrm{S}$. mutans and A. viscosus comparing to other material such as $\mathrm{CH}$ and FS [7]. However, the sealing ability of MTA is considered as the one of its main advantages and based on a study which researched the microleakage of MTA in pulpotomies in primary molars, MTA presents significant less microleakage than other used materials with the condition that MTA is used in a dry environment [51]. From a histological sight, MTA results to the formation of the homogenous crystalline structure in the surface of its use and it can lead to a dentine bridge formation which works as a protective barrier for the remaining pulp tissue. It has been found that comparing to $\mathrm{CH}$ this dentine bridge is thicker and it is also extremely important that the pulp tissue responses to the use of MTA with less inflammation, less hyperemia and the necrosis is also very limited [36]. However, MTA has some disadvantages and limitations such as its high cost, difficult in manipulation, tooth discoloration and long setting time [52].

MTA is a material which has been researched a lot the last years and it has shown very positive results in cases of 
pulpotomy in primary molars comparable to the formocresol. In a clinical study which compared FS and MTA as pulpotomy agents it was presented that at the 12 months follow-up the radiographic success rate of MTA was $96 \%$ without any clinical signs of failure [53]. Reference [13] also confirmed the superior success rates of MTA and their study resulted to $100 \%$ overall success rate after 12 and 18 months. According to another clinical study, pulpotomy in primary molars with MTA had 95\% success rate at 12- and 24-months follow-ups with furcation radiolucency as the only radiographic sign [36]. Reference [54] presented in their clinical trial that the success rate of MTA group was $96 \%$ at 24 months follow up. Reference [55] also found that the radiographic success rate after 12 months is $96 \%$ and the only failure sign was internal resorption, which was then arrested with the replacement by calcified material. Reference [56] performed pulpotomy on 90 decayed primary molars with MTA and Biodentine and the outcomes of the clinical trial presented that at since the 9 months follow up the MTA group had $100 \%$ clinical and radiographic success rate and at the 12 months follow up the clinical success rate decreased to $95.5 \%$ and also only one tooth presented radiographic signs such as interradicular radiolucency and periodontal ligament widening. Additionally, according to [57] the MTA group in a clinical trial of 140 teeth in total presented the high clinical success rate of $100 \%$ at 24 months follow up and also $93,9 \%$ of the teeth treated with MTA had no radiographic signs of failure. Reference [58] divided primary molars in two group and they performed pulpotomy with MTA and Biodentine. They evaluated the pulpotomised teeth at 12,18 , and 24 months follow ups and the results showed that the clinical success rate at the last follow up was $96.8 \%$ for both two medicaments while also the radiographic success rate of the MTA group was $87,1 \%$. Reference [6] also observed in their clinical study the impressive results of MTA which had $92 \%$ success rate at 12 months follow-up with the internal resorption as the main radiographic sign. Furthermore, based on the clinical trial of [59] MTA showed 100\% clinical and radiographic success rate 12 months after the pulpotomy procedure. Also, [42] performed pulpotomy with MTA in 27 primary teeth and the clinical and radiographic findings at 12 and at 24 months follow ups showed 100\% success. Reference [60] also evaluated the effectiveness of MTA as pulpotomy agent and they found that at 24 months follow up the overall success rate of MTA group was $97.2 \%$.

\section{F. Portland Cement}

The fact that MTA has been proved to be a material of choice for pulpotomy but with limitations as its high cost and the difficulty in its clinical use has led to the focus on the evolution of Portland Cement (PC). PC and MTA have many similarities in their structure as the $\mathrm{PC}$ is the main chemical component of MTA with the absence of bismuth ions and the presence of potassium ions in PC as the only differences between these two materials [61]. PC has also similar properties with MTA such as similar antibacterial activity and the ability to promote dentine bridge formation, but it is in some cases more preferable due to its lower-cost. However, $\mathrm{PC}$ has been related to a limitation regarding the radiopacity absence, which makes the addition of a radiopacifier necessary [61], [62]. Reference [62] researched through a clinical study the effectiveness of PC as a pulpotomy material and they also compared this medicament to MTA. The overall success rate was $100 \%$ after 12 and 24 months and there was no sign of pain, sinus, mobility or swelling and nonradiographic sign of failure such as internal resorption or/and furcation radiolucency. Worth mentioning is also that dentine bridge formation was found in 2 of the 15 pulpotomised teeth at all follow-ups appointments. In addition, crown discolouration was observed in all pulpotomised teeth, but this feature was slighter in teeth treated with PC. Also, [61] confirmed the promising results of this material as the success rate of PC was also $100 \%$ at 6 , 12-, and 24-months follow-ups. Reference [57] performed pulpotomy in 45 primary molars with $\mathrm{PC}$, then the teeth were restored with stainless steel crows and the outcome of the trial was that this group had at 24 months follow up 93,9\% and $86,7 \%$ clinical and radiographic success rate respectively. Furthermore, [63] confirmed the effectiveness of PC because the success rate at 12 months follow up was $100 \%$, while also [64] found that PC led to completely successful results, and it is also very important that dentine bridge was present in some pulpotomised teeth. According to [65], histological description of PC has shown no inflammation and formation of dentin-like material which led to root canal obliteration.

\section{G. Biodentine}

Biodentine was firstly introduced in 2009 [66] and it is another calcium silicate cement with high alkaline $\mathrm{pH}$ [67]. Biodentine consists of a powder which is composed of tricalcium silicate, zirconium oxide and calcium carbonate and of a liquid which is mostly water, and it also contains water-soluble polymer and calcium chloride to obtain rapid setting time and high strengh [13], [52]. It has the MTA-based cement technology and therefore it combines the advantages of MTA with some other better properties such as better and more convenient handling [66]. It is also a material which promotes dentine bridge formation and compared to calcium hydroxide has the ability to produce tighter seals [32]. Biodentine has presented good properties such efficient sealing ability, antimicrobial activity [66], quick setting time, biocompatibility, ability to promote hard tissue regeneration, stability, low solubility, and long-term impermeability [15].

Biodentine has been the last years researched and it has been compared to other pulpotomy medicaments with successful results. Reference [56] researched the effectiveness of Biodentine as pulpotomy agent and they showed through their clinical trial in 45 primary molars that this material had $95.5 \%$ clinical and radiographic success rate at 12 months follow up. Reference [15] demonstrated the outstanding results of Biodentine through their clinical trial in 112 primary molars and it was shown that at 12 months follow-up the overall success rate was $100 \%$. Reference [32] confirmed the promising results of this medicament and they conducted a clinical trial in 400 primary molars in order to compare Biodentine and calcium hydroxide. They found that Biodentine led to better results as the clinical success rate was $96.5 \%$ and the radiographic one $90.1 \%$ after 18 months with resorption and periodontal ligament widening the most often signs of failure. Reference [13] came to the conclusion that Biodentine showed $93.3 \%$ radiographic success rate at 12 months follow-up but this rate dropped to $86.7 \% 18$ months 
after the pulpotomy procedure due to internal resorption and furcation radiolucency. Reference [67] compared Biodentine and MTA and the results of this clinical study showed that the total success rate of Biodentine was $89.4 \%$ at 12,18 , and 24 months follow-ups which was a little lower that the rate of MTA but this difference was characterized as insignificant. Also, [68] compared Biodentine and formocresol and they presented that Biodentine had 97,3\% success rate which was higher than the success rate of the old gold standard, while [66] also confirmed the high effectiveness of Biodentine as a pulpotomy medicament as the overall success rate of this material in their clinical trial was $94 \%$ at 9 months follow up. The study of [60] also presented that Biodentine led to great results as they revealed that this medicament had 97,4\% overall success rate at the 24 months follow up.

\section{H. Sodium Hypochlorite}

Sodium Hypochlorite (SH) was used at first in the field of dentistry as an irrigant agent in root canal treatments in permanent teeth since 1920s [69]. Nowadays it is a material of choice for hemostasis, removal of debris and biofilm, irrigation of root canals and it is also used as a medicament for pulpotomy in primary teeth [17]. SH has very good antibacterial properties and Rosenfeld, [70] have shown that $5 \% \mathrm{NaOCL}$ acts only superficially without being irrigant to the deeper pulp tissue. Reference [71] showed that after the use of $3 \% \mathrm{NaOCL}$, a normal soft tissue reorganization and dentinal bridge formation were observed in $86 \%$ of the treated pulps. Reference [72] came to the result that 3\% NaOCL can be used as a medicament in pulpotomies and that this material is related to promising results and to normal pulps when the microleakage in the pulp-restoration surface is also limited. Reference [73] presented also that 5\% NaOCL has showed successful results as a medicament for pulpotomies with $100 \%$ clinical and $79 \%$ radiographic success rate at 12 months follow-up. Reference Bawazir [74] presented in their clinical trial that the pulpotomised primary molars of the $\mathrm{SH}$ group had $94,6 \%$ and $86,5 \%$ clinical and radiographic success rate respectively. In addition, [69] based on 147 pulpotomised primary molars with NaOCL performed follow ups at 6,12 and 24 months and they found that the clinical success rate was $97 \% 12$ months after the pulpotomy procedure and that this rate remained the same until the last of the follow up period. Also, in the same research the radiographic success rate was $89 \%$ at the second follow up but this rate dropped to $77 \%$ at the last evaluation. Reference [75] revealed that the group of primary molars which were pulpotomised with $\mathrm{NaOCL}$ presented $100 \%$ and $85 \%$ clinical and radiographic success rates at 6 months follow up respectively. Furthermore, histologic studies also showed that $\mathrm{SH}$ is a suitable material for pulpotomies because compared to formocresol, SH leads less to severe inflammation of the pulp tissue, and it can also promote dentinal bridge formation maybe due to the maintenance of the pulp vitality [17].

\section{Electrosurgery}

Electrosurgery (ES) is an alternative, non-pharmacological pulpotomy technique which seems to have promising results, and which can lead to good visualisation and hemostasis [38]. The mechanism of its action has been researched and it is now known that the procedure of ES carbonizes and denatures the pulp tissue, and the result is the production of a layer of coagulative necrosis which protects the remaining pulp tissue beneath the lining base material [76]. Reference [77] compared the success rates between pulpotomy with electrosurgery and pulpotomy with the old gold-standard formocresol and this study showed that the clinical success rate of ES pulpotomy was $96 \%$ and the radiographic $84 \%$ with root resorption and internal root resorption the most common radiographic signs of failure, while formocresol led to better results but the difference between them was statistically insignificant. Reference [37] also confirmed the successful results of ES as their clinical trial showed that the radiographic success rate at 12 months follow-up was $98 \%$ without any clinical symptoms. Reference [43] divided 45 primary molars equally in three groups and the clinical and radiographic success rates of the ES group at 9 months follow up were $100 \%$ and $80 \%$ respectively with internal resorption the most frequent sign of failure. Also, [45] found that ES led in their clinical trial to $80 \%$ clinical and radiographic success rate in a group of ten pulpotomised primary molars at 12 months follow up.

\section{J. Laser}

Laser is a nonconventional, non-pharmacological technique, which has been recommended the last decades in different endodontic treatments including pulpotomy [78]. Laser is considered to present important advantages such as the potential to promote healing, to stimulate dentinogenesis and to preserve the vitality of the remaining pulp tissue [66]. Laser treatment can also provide control of hemorrhage, sterilization and the possibility to remove the soft tissue without causing trauma to the residual tissues [79]. The need to find new materials and techniques which can be used in pulpotomy procedure with efficient results and the promising advantages of laser led the last years to the investigation of several laser types such as diode, carbon dioxide, argon, Er:Yag and Nd:Yag laser.

Diode laser is considered to be suitable for pulpotomy treatment because of its high absorbance at the wavelength at which energy is produced in dental pulp tissue and its potential to leave the other tissues unaffected. Studies have also shown that laser pulpotomy compared to formocresolZOE pulpotomy has a reduced radiographic success rate, which was statistically insignificant while also all patients were free of symptoms and clinical signs of failure [80]. Reference [45] showed that the diode laser group in their clinical trial presented $100 \%$ overall success rate and that this pulpotomy technique was the most successful compared to the groups of electrosurgery and ferric sulfate of their study. In addition, [81] evaluated the success rate of a carbon dioxide laser pulpotomy and they found that this treatment option presented comparable results which a conventional pulpotomy with formocresol. Er:Yag laser is also an alternative as it is hemostatic, antimicrobial and because it has cell-stimulating properties. Reference [14] compared the results of Er:Yag laser pulpotomy with other three more conventional techniques and they found that the overall success rate of laser therapy was $93 \%$ and $78 \%$ at the 12 months and the 24 months follow-up respectively, which difference was insignificant with the success rate of the old gold standard formocresol. In another study, which evaluated the pulpotomy using Er:Yag laser, Biodentine and MTA, 
results showed that the success rate of pulpotomy with laser was $78.5 \%$ after 9 months which was lower compared to other two groups but the researchers concluded that Er:Yag laser can effectively be used in pulpotomy procedure [66]. Furthermore, [82] investigated the bacteridical effect of $\mathrm{Nd}$ :Yag laser and they achieved to eliminated the bacteria in the root canals to $99.9 \%$. Also, in a study of [79] 42 teeth were pulpotomised in order to compare the results of pulpotomy with Nd:Yag laser and formocresol and the clinical trial showed that the clinical success rate of $\mathrm{Nd}$ :Yag laser pulpotomy was $85.71 \%$ at the 12 months follow-up and the radiographic success rate was $71.42 \%$ and the difference between the two groups was considered statistically insignificant.

\section{K. Zinc Oxide Eugenol}

Zinc oxide eugenol (ZOE) has been used many years as a coronal dressing material after the use of a pulpotomy agent for the amputation of the dental pulp. ZOE is an antibacterial material with low cost, which is easy to handle during clinical procedures [83] but due to eugenol was not recommended for direct contact with the pulp tissue [84]. However, there are a few studies which have researched the effectiveness of ZOE as pulpotomy material. Reference [85] found that the sterile compression of ZOE or ferric sulfate in 145 primary molars led in both groups to $100 \%$ success rate after 3 months. Also, [86] performed pulpotomy in 190 primary molars with reinforced $\mathrm{ZOE}$ as the only pulpotomy agent and the clinical and radiographic success rates were $97 \%$ and $95 \%$ respectively. Reference [87] also evaluated ZOE as pulpotomy medicaments and for this reason they performed pulpotomy in 60 decayed primary molars and the outcomes of the trial showed that at 24 months follow up 51/60 pulpotomised teeth had not clinical or radiographic signs of failure. The other 9 teeth presented clinical symptoms and regarding the radiographic signs the most frequent were furcal and periapical radiolucency and root resorption. According to [54], the success rate of ZOE as the only pulpotomy medicament was $68 \%$ at 24 months follow up, which was significantly lower than the MTA group in the same clinical trial.

\section{Calcium Enriched Mixture Cement}

Calcium enriched mixture cement (CEM) is a calcium silicate-based cement, which was firstly used in dentistry in 2006. It consists of a liquid and a powder, which mostly contains calcium oxide, sulfur trioxide, phosphorous pentoxide, and silicon dioxide. It has specific features with great significance such as high biocompatibility, antimicrobial activity, and primary setting time, but also worth mentioning is its ability to promote dentine bridge formation [88], [89]. Reference [37] compared the success rates of CEM and electrosurgery through a clinical trial on 102 primary molars and they presented that CEM led to $90 \%$ radiographic success without any clinical signs of failure at 24 months follow-up.

\section{Calcium Phosphate Cement}

Calcium phosphate cement (CPC) is a hydraulic cement which has been researched as a pulpotomy medicament. Reference [90] came to the conclusion that this material maybe belongs to the future pulpotomy medicaments.
Furthermore, [91] also evaluated the suitability of CPC and therefore they performed pulpotomy on canines and the histological examination showed that CPC led to less inflammation of the remaining dental pulp in comparison to formocresol and also that CPC promoted the dental bridge formation.

\section{N. Lyophilized Platelet-Derived Preparation}

Lyophilized platelet-derived preparation (LPDP) has also focused the interest as a potential pulpotomy agent and based on the clinical trial of [92], it was used as a pulpotomy medicament on 28 teeth, which were evaluated at 1, 3 and 6 months follow ups, and it was proved that it led to better results in comparison with the other group of teeth which were pulpotomised with calcium hydroxide. Additionally, [93] performed pulpotomy on 40 primary molars with platelet-rich fibrin and LPDP in order to compare these two pulpotomy agents and the results showed that LPDP had 95\% success rate at 6 months follow up, which was better outcome than the success rate of the other group.

\section{O. Platelet-Rich Fibrin}

Platelet-rich fibrin (PRF) has also been researched as a material for pulpotomy in primary teeth. It is an autologous material, which is according to [93] a promising medicament for pulpotomy as they found in this clinical trial that this material can achieve $90 \%$ success rate at the 6 months followup. Also, [94] evaluated the effectiveness of PRF and they compared it to MTA through a clinical trial on 50 primary molars and the results of the study showed that the overall success rate was $90 \% 6$ months after the pulpotomy procedure.

\section{P. Recombinant human platelet-derived growth factor}

Recombinant human platelet-derived growth factor (rhPDGF) presents the ability to promote dentinogenesis but the mechanism of its action has not since today totally understood. Reference [95] and [96] researched the rhPDGF in combination with MTA and with $\mathrm{Ca}(\mathrm{OH})_{2}$ in two different clinical trials and they confirmed the presence of a hard tissue formation of a dentine-like structure with normal features such as porosity and efficient thickness in the rhPDGF+MTA group and worth mentioning is that this structure presented similar features with the secondary dentin. Also, in the other study they found that in the $\mathrm{rhPDGF}+\mathrm{Ca}(\mathrm{OH})_{2}$ a hard tissue formation was also present but with the difference that in this group this structure was not consistent and it had also differences in comparison to the secondary dentin.

\section{Q. Bioactive Glass}

Bioactive glass belongs to the class of osteoconductive biomaterials, which presents the property to produce a superficial layer of hydroxycarbonate apatite [97], [98]. Reference [97] researched the bioactive glass as potential pulpotomy medicament through an in vivo study on rat molars and the histological evaluation showed at 2 weeks the presence of pulpal inflammation which was severe enough to provoke internal resorption in a sample and periapical abscess formation in another sample. Although, at 4 weeks evaluation the initial inflammation seemed to be limited. In addition, [99] showed that bioactive glass led to $100 \%$ clinical and $84 \%$ radiographic success rate 12 months after the pulpotomy 
procedure. Although, [100] in order to compare the 70S30C bioactive glass to Biodentine, they pulpotomised primary teeth and they performed follow ups until 12 months after the pulpotomy procedure. The results showed that at 3 months follow up all teeth in the group of bioactive glass presented clinical signs of failure due to persisting inflammation.

\section{R. Hydroxyapatite Crystals}

Hydroxyapatite is the main component of the inorganic part of the hard tissue of the teeth, and it has been also the last years researched as a pulpotomy agent. Reference [101] performed pulpotomy on primary molars with hydroxyapatite and the results of this clinical trial showed $80.33 \%$ radiographic success rate without clinical symptoms at 6 months follow up. Reference [102] performed pulpotomy on pig teeth and the histological evaluation showed absence of severe inflammation and also the researchers came to the conclusion that hydroxyapatite can be a suitable material for pulpotomy. Furthermore, [99] found in their clinical trial on pulpotomised primary molars that the pulpotomy with hydroxyapatite crystals showed $100 \%$ clinical and $84 \%$ radiographic success rate at 12 months follow up.

\section{S. Freeze-Dried Bone}

Freeze-dried bone was evaluated from [103] as a pulpotomy agent and they performed pulpotomy on primary and permanent teeth of monkeys. The histological evaluation showed that the pulpotomised teeth maintained the vitality of the apical part of the remaining pulp tissue and also worth mentioning is the presence of a calcific barrier in all but three teeth.

\section{T. Bone Morphogenetic Proteins}

Bone morphogenetic proteins (BMPs) is a family of proteins, which have bone-inductive properties and they are implicated in cell differentiation, tissue morphogenesis, regeneration, and repair. Studies based on animals have shown that BMP has the potential to stimulate the induction and differentiation of mesenchymal cells with varying degrees of dentine bridge formation [12]. Other studies have also presented that BMP-7 may be able to mediate epithelialmesenchymal interactions during the initiation phase of odontogenesis and morphogenesis [104]. Although, in a study on pulpotomised animals' teeth, BMP-7 and BMP-2 were not able to induce dentine formation [105].

\section{U. Enamel Matrix Derivative}

Enamel matrix derivative (EMD) is a protein extract from unerupted porcine tooth buds, which contains $90 \%$ amelogenins and smaller amounts of tuftelin, ameloblastin, enamelin and other nonamelogenin proteins and it is used for the treatment of periodontal defects and soft tissue recession [106]. Reference [107] showed with their study on pigs' teeth that EMD can lead to better results than $\mathrm{Ca}(\mathrm{OH})_{2}$ because it can promote dentine bridge formation without affecting the remaining pulp tissue. Although, an another study on dogs from [108] presented that EMD led earlier than $\mathrm{Ca}(\mathrm{OH})_{2}$ to the formation of dentine bridge but the EMD group presented after three months pulpal inflammation and disintegration of the pulp.

\section{Collagen}

Cross-linked collagen gel and enriched collagen solution have been reported as pulpotomy medicaments in animals. Studies have shown different responses including complete regeneration of the pulp tissue and dentine bridge formation, but it is worth to mention that these studies were carried out only on non-inflamed pulps [12]. Reference [109] demonstrated that a commercial collagen preparation with the name Zyderm (Colagen Corp. Palo Alto, CA) led to unacceptable results because only $4 \%$ presented dentine bridge formation and the collagen group was also related to total or partial necrosis and severe inflammation. However, an in vivo study, which compared collagen-based pulpotomy and conventional pulpotomy with formocresol, showed very promising results as the collagen group led overall to higher success rate [110].

\section{DisCUSSION-CONCLUSION}

Pulpotomy is a type of vital pulp treatment, which can lead to high success rates, when it is selected as a treatment of choice with strict criteria. The right diagnosis, the right selection of patients who present reversible pulp inflammation due to caries or trauma, the performance of the pulpotomy technique with proper isolation and with the suitable technique and medicament and also a final restoration, which is against microleakage are among the most important key factors for the success of the pulpotomy. Reference [111] researched the prognostic factors for the success of the pulpotomy with MTA and the outcomes of the study showed that important role also plays the type of the arch and the tooth as it was proved that mandibular deciduous molars were related to higher failure rate. Furthermore, pulpotomy on primary molars with caries below the cementoenamel junction had worse results in comparison with the pulpotomised molars with less extended caries and significant was the type of the final restoration as the stainless-steel crowns were proved to be the most reliable and proper choice.

The selection of the right pulpotomy medicament is also considered to be crucial in order a pulpotomised primary tooth to maintain its vitality and to maintain also in the arch until its normal exfoliation. The ideal pulpotomy material has to be biocompatible, antibacterial, harmless to the surrounding tissues, no irritating to the pulp tissue and it is also important that this material can promote the healing of the remaining pulp and not interfere the normal root resorption of the deciduous teeth. Nowadays there is a variety of medicaments, which can be used for the procedure of pulpotomy in primary teeth. Formocresol was the old gold standard because of the many clinical trials which proved the high success rates of this medicament but the last years its use has been limited due to serious concerns about its safety. Moreover, glutaraldehyde is not considered as a suitable pulpotomy medicament not only for safety reasons but also because it led to worse success rates compared to other medicaments. Also, it has been proved that calcium hydroxide leads to lower clinical and radiographic success rates with the root resorption the most frequent cause of failure and it is no longer recommended as a pulp dressing 
material. However today, materials as ferric sulfate, MTA, Biodentine and Portland cement are among the most favorable pulpotomy agents with very important advantages and great effectiveness. Ferric sulfate proved to be a safe material with clinical results comparable to the old gold standard and the fact that ferric sulfate has less setting time, makes it easier to handle during the clinical procedure of pulpotomy. Based on the results of the clinical studies which are included in this review, the success rate of ferric sulfate is between $80-97,2 \%$ with the only exception of one study which resulted in $70 \%$ success rate of this medicament. Also, MTA has led to great outcomes and a high effectiveness between $87.1 \%-100 \%$ and therefore it is considered to be a material of choice, but it has some limitations such as its high price and its difficulty in manipulation. Furthermore, the discoloration is an another very important disadvantage of MTA because it limits the use of this material on anterior teeth for aesthetic reasons. Biodentine and Portland cement seem to be also suitable choices with high overall success rates. Furthermore, electrosurgery is an alternative nonpharmacological technique with success rate not lower than $80 \%$ according to the above clinical trials. Laser is another non-conventional technique for pulpotomy, which have led according to studies also to positive results depending also on the type of the selected laser. Sodium hypochlorite has shown the last years that it is a promising medicament with antibacterial properties and the significant property to maintain the vitality of the remaining pulp tissue, while also its effectiveness is based on the literature not lower than $77 \%$ 24 months after the pulpotomy procedure. Zinc oxide eugenol was researched in a few studies as pulpotomy medicament, and the results were quite controversial because of the significant difference between the success rates of this material in the above clinical trials. Also, many medicaments including calcium enriched cement, calcium phosphate cement, bioactive glass and hydroxyapatite crystals have been more researched the last years and the studies showed promising results and that these materials can be potential alternatives for pulpotomy, but more research is needed. Regarding the platelet rich fibrin and the lyophilized plateletderived preparation were evaluated and compared to other more conventional pulpotomy agents in a few research and the success rates seem to be also high, whereas recombinant human platelet-derived growth factor showed to have the ability to promote dentine-bridge formation. Additionally, freeze-dried bone, bone morphogenetic proteins, enamel matrix derivative and collagen have been researched but since today there are almost only studies on animals.

\section{CONFLICT OF INTEREST}

Authors declare that they do not have any conflict of interest.

\section{REFERENCES}

[1] Who.int. Oral Health [Internet]. 2020 [updated 2020 March 25]. Available from: https:/www.who.int/news-room/factsheets/detail/oral-health

[2] Frencken JE, Sharma P, Stenhouse L, Green D, Laverty D, Dietrich T. Global epidemiology of dental caries and severe periodontitis - a comprehensive review. J Clin Periodontol. 2017; 44(18): 94-105.
[3] Bjørndal L, Simon S, Tomson PL, Duncan HF. Management of deep caries and the exposed pulp. Int Endod J. 2019; 52(7): 949-973.

[4] American Academy of Pediatric Dentistry. Pulp therapy for primary and immature permanent teeth. The Reference Manual of Pediatric Dentistry. Chicago, Ill.: American Academy of Pediatric Dentistry; 2020:384-92

[5] Fuks AB. Vital pulp therapy with new materials for primary teeth: new directions and Treatment perspectives. Pediatr Dent. 2008; 30(3): 211 9.

[6] Rajasekharan S, Martens LC, Vandenbulcke J, Jacquet W, Bottenberg $\mathrm{P}$, Cauwels RG. Efficacy of three different pulpotomy agents in primary molars: a randomized control trial. Int Endod J. 2017; 50(3): 215-228.

[7] Pimenta HC, Borges AH, Bandeca MC, Neves AT, Fontes RG, da Silva $\mathrm{PV}$, et al. Antimicrobial activity of filling materials used in primary teeth pulpotomy. J Int Oral Health. 2015; 7(4): 54-57.

[8] Pinkham JR, Casamassimo PS, McTigue DJ, Fields HW \& Nowak AJ Pulp therapy for the primary dentition. Pediatric dentistry: Infancy through adolescence. 4th edition. St.Louis, Missouri. Elsevier Saunders, 2005; 22: 375-393.

[9] Buckley JP. The chemistry of pulp decomposition with a rational treatment for this condition and its sequelae. American Dental Journal 1904; 3: 764-771.

[10] Sweet CA, Jr. Procedure for treatment of exposed and pulpless deciduous teeth. Journal of the American Dental Association. 1930; 17: 1150-1153.

[11] Chakraborty A, Dey B, Jana S. A Nonconventional approach to formocresol pulpotomy. Int J Clin Pediatr Dent. 2018; 11(6): 490-495.

[12] Srinivasan V, Patchett CL, Waterhouse PJ. Is there life after Buckley's Formocresol? Part I -- a narrative review of alternative interventions and materials. Int J Paediatr Dent. 2006; 16(2): 117-27.

[13] Juneja P, Kulkarni S. Clinical and radiographic comparison of biodentine, mineral trioxide aggregate and formocresol as pulpotomy agents in primary molars. Eur Arch Paediatr Dent. 2017; 18(4): 271278 .

[14] Huth KC, Paschos E, Hajek-Al-Khatar N, Hollweck R, Crispin A, Hickel R, et al. Effectiveness of 4 pulpotomy techniques--randomized controlled trial. J Dent Res. 2005; 84(12): 1144-8.

[15] El Meligy OAES, Alamoudi NM, Allazzam SM, El-Housseiny AAM. Biodentine TM versus formocresol pulpotomy technique in primary molars: a 12-month randomized controlled clinical trial. BMC Oral Health. 2019; 19(1): 3 .

[16] Ruby JD, Cox CF, Mitchell SC, Makhija S, Chompu-Inwai P, Jackson J. A randomized study of sodium hypochlorite versus formocresol pulpotomy in primary molar teeth. Int J Paediatr Dent. 2013; 23(2): 145-52.

[17] Haghgoo R, Abbasi F. A histopathological comparison of pulpotomy with sodium hypochlorite and formocresol. Iran Endod J. 2012 Spring; $7(2): 60-2$.

[18] Lewis BB, Chestner SB. Formaldehyde in dentistry: a review of mutagenic and carcinogenic potential. J Am Dent Assoc. 1981; 103(3): 429-34.

[19] Zarzar PA, Rosenblatt A, Takahashi CS, Takeuchi PL, Costa Júnior LA. Formocresol mutagenicity following primary tooth pulp therapy: an in vivo study. $J$ Dent. 2003; 31(7): 479-85.

[20] Milnes AR. Is formocresol obsolete? A fresh look at the evidence concerning safety issues. J Endod. 2008; 34(7): 40-6.

[21] Casas MJ, Kenny DJ, Judd PL, Johnston DH. Do we still need formocresol in pediatric dentistry? J Can Dent Assoc. 2005; 71(10): 749-51.

[22] Swenberg JA, Kerns WD, Mitchell RI, Gralla EJ, Pavkov KL. Induction of squamous cell carcinomas of the rat nasal cavity by inhalation exposure to formaldehyde vapour. Cancer Research. 1980; 40: 3398-3402.

[23] Patchett CL, Srinivasan V, Waterhouse PJ. Is there life after Buckley's formocresol? Part II - Development of a protocol for the management of extensive caries in the primary molar. Int J Paediatr Dent. 2006; 16(3): 199-206.

[24] Ribeiro DA, Marques ME, Salvadori DM. Lack of genotoxicity of formocresol,paramonochlorophenol and calcium hydroxide on mammalian cells by commet assay. J Endod. 2004; 30: 593-6.

[25] Ribeiro DA, Scolastici C, De Lima PL, Marques ME, Salvodori DM. Genotoxicity of antimicrobial endodontic compounds by single cell gel (comet) assay in Chinese hamster ovary (CHO) cells. Oral Surg Oral Med Oral Pathol Oral Radiol Endod. 2005; 99: 637-40.

[26] Waterhouse PJ. Formocresol and alternative primary molar pulpotomy medicaments: a review. Endod Dent Traumatol. 1995; 11: 157-162.

[27] Fuks AB, Bimstein E, Kelin H. Assessment of a 2 percent buffered glutaraldehyde solution in pulpotomized primary teeth of school 
children: a preliminary report. Journal of Pedodontics. 1986; 10: 323 330 .

[28] Goyal P, Pandit IK, Gugnani N, Gupta M, Goel R, Gambhir RS. Clinical and radiographic comparison of various medicaments used for pulpotomy in primary molars: A randomized clinical trial. Eur J Dent. 2016; 10: 315-20.

[29] Tsai TP, Su HL, Tseng LH. Glutaraldehyde preparations and pulpotomy in primary molars. Oral Surg Oral Med Oral Pathol. 1993; 76(3): 346-50.

[30] Abbott PV. Apexification with calcium hydroxide--when should the dressing be changed? The case for regular dressing changes. Aust Endod J. 1998; 24(1): 27-32.

[31] Zinman EJ. Calcium Hydroxide. J Am Dent Assoc. 2020; 151(8): 553.

[32] Caruso S, Dinoi T, Marzo G, Campanella V, Giuca MR, Gatto R, et al. Clinical and radiographic evaluation of biodentine versus calcium hydroxide in primary teeth pulpotomies: a retrospective study. $B M C$ Oral Health. 2018; 18(1): 54.

[33] Bossù M, Iaculli F, Di Giorgio G, Salucci A, Polimeni A, Di Carlo S. Different pulp dressing materials for the pulpotomy of primary teeth: A systematic review of the literature. J Clin Med. 2020; 9(3): 838.

[34] Liu H, Zhou Q, Qin M. Mineral trioxide aggregate versus calcium hydroxide for pulpotomy in primary molars. Chin J Dent Res. 2011; 14(2): 121-5.

[35] Celik B, Ataç AS, Cehreli ZC, Uysal S. A randomized trial of mineral trioxide aggregate cements in primary tooth pulpotomies. J Dent Child (Chic). 2013; 80(3): 126-32.

[36] Subramaniam P, Konde S, Mathew S, Sugnani S. Mineral trioxide aggregate as pulp capping agent for primary teeth pulpotomy: 2 year follow up study. J Clin Pediatr Dent. 2009; 33(4): 311-4.

[37] Khorakian F, Mazhari F, Asgary S, Sahebnasagh M, Alizadeh Kaseb A, Movahhed T, et al. Two-year outcomes of electrosurgery and calcium-enriched mixture pulpotomy in primary teeth: a randomised clinical trial. Eur Arch Paediatr Dent. 2014; 15(4): 223-8.

[38] Farrokh Gisoure E. Comparison of three pulpotomy agents in primary molars: a randomised clinical trial. Iran Endod J. 2011; 6(1): 11-4.

[39] Sirohi K, Marwaha M, Gupta A, Bansal K, Srivastava A. Comparison of Clinical and Radiographic Success Rates of Pulpotomy in Primary Molars using Ferric Sulfate and Bioactive Tricalcium Silicate Cement: An in vivo Study. Int J Clin Pediatr Dent. 2017; 10(2): 147-151.

[40] Sivadas S, Rao A, Natarajan S, Shenoy R, Srikrishna SB. Pulpal response to ferric sulfate and diode laser when used as pulpotomy agent: An in vivo study. J Clin Diagn Res. 2017; 11(6): ZC87-ZC91.

[41] Ibricevic H, al-Jame Q. Ferric sulfate as pulpotomy agent in primary teeth: twenty month clinical follow-up. J Clin Pediatr Dent. 2000; 24(4): 269-72.

[42] Lin YT, Lin YJ. Success rates of mineral trioxide aggregate, ferric sulfate, and sodium hypochlorite pulpotomies: A prospective 24-month study. J Formos Med Assoc. 2020; 119(6): 1080-1085.

[43] Yadav P, Indushekar K, Saraf B, Sheoran N, Sardana D. Comparative evaluation of Ferric Sulfate, Electrosurgical and Diode Laser on human primary molars pulpotomy: an "in-vivo" study. Laser Ther. 2014; 23(1): 41-7.

[44] Guven Y, Aksakal SD, Avcu N, Unsal G, Tuna EB, Aktoren O. Success rates of pulpotomies in primary molars using calcium silicate-based materials: A randomized control trial. Biomed Res Int. 2017; 2017 : 4059703 .

[45] Gupta G, Rana V, Srivastava N, Chandna P. Laser Pulpotomy-An Effective Alternative to Conventional Techniques: A 12 Months Clinicoradiographic Study. Int J Clin Pediatr Dent. 2015; 8(1): 18-21.

[46] Farsi DJ, El-Khodary HM, Farsi NM, El Ashiry EA, Yagmoor MA, Alzain SM. Sodium hypochlorite versus formocresol and ferric sulfate pulpotomies in primary molars: 18-month follow-up. Pediatr Dent. 2015; 37(7): 535-40.

[47] Ozmen B, Bayrak S. Comparative evaluation of ankaferd blood stopper, ferric sulfate, and formocresol as pulpotomy agent in primary teeth: A clinical study. Niger J Clin Pract. 2017; 20(7): 832-838.

[48] Junqueira MA, Cunha NNO, Caixeta FF, Marques NCT, Oliveira TM, Moretti ABDS, et al. Clinical, radiographic and histological evaluation of primary teeth pulpotomy using MTA and ferric sulfate. Braz Dent J. 2018; 29(2): 159-165.

[49] Fang RR, Chang KY, Lin YT, Lin YJ. Comparison of long-term outcomes between ferric sulfate pulpotomy and indirect pulp therapy in primary molars. $J$ Dent Sci. 2019; 14(2): 134-137.

[50] Brar KA, Kratunova E, Avenetti D, da Fonseca MA, Marion I, Alapati $\mathrm{S}$. Success of Biodentine and ferric sulfate as pulpotomy materials in primary molars: A retrospective study. J Clin Pediatr Dent. 2021; 45(1): $22-28$

[51] Farto J, Canalda Sahli C, Boj JR. Microleakage of MTA in primary molar pulpotomies. Eur J Paediatr Dent. 2017; 18(3): 183-187.
[52] Carti O, Oznurhan F. Evaluation and comparison of mineral trioxide aggregate and biodentine in primary tooth pulpotomy: Clinical and radiographic study. Niger J Clin Pract. 2017; 20: 1604-9.

[53] Olatosi OO, Sote EO, Orenuga OO. Effect of mineral trioxide aggregate and formocresol pulpotomy on vital primary teeth: A clinical and radiographic study. Niger J Clin Pract 2015; 18: 292-6.

[54] Erdem AP, Guven Y, Balli B, Ilhan B, Sepet E, Ulukapi I, et al. Success rates of mineral trioxide aggregate, ferric sulfate, and formocresol pulpotomies: a 24-month study. Pediatr Dent. 2011; 33(2): 165-70.

[55] Godhi B, Tyagi R. Success rate of MTA pulpotomy on vital pulp of primary molars: A 3-Year observational study. Int J Clin Pediatr Dent. 2016; 9(3): 222-227.

[56] Togaru H, Muppa R, Srinivas N, Naveen K, Reddy VK, Rebecca VC. Clinical and radiographic evaluation of success of two commercially available pulpotomy agents in primary teeth: An in vivo study. $J$ Contemp Dent Pract. 2016; 17(7): 557-63.

[57] Yildirim C, Basak F, Akgun OM, Polat GG, Altun C. Clinical and radiographic evaluation of the effectiveness of formocresol, mineral trioxide aggregate, Portland cement, and enamel matrix derivative in primary teeth pulpotomies: A two-year follow-up. J Clin Pediatr Dent. 2016; 40(1): 14-20.

[58] Bani M, Aktaş N, Çınar Ç, Odabaş ME. The clinical and radiographic success of primary molar pulpotomy using Biodentine ${ }^{\mathrm{TM}}$ and mineral trioxide aggregate: A 24-month randomized clinical trial. Pediatr Dent. 2017; 39(4): 284-288.

[59] Silva LLCE, Cosme-Silva L, Sakai VT, Lopes CS, Silveira APPD, Moretti Neto RT, et al. Comparison between calcium hydroxide mixtures and mineral trioxide aggregate in primary teeth pulpotomy: a randomized controlled trial. J Appl Oral Sci. 2019; 27: e20180030.

[60] Vilella-Pastor S, Sáez S, Veloso A, Guinot-Jimeno F, Mercadé M. Long-term evaluation of primary teeth molar pulpotomies with Biodentine and MTA: a CONSORT randomized clinical trial. Eur Arch Paediatr Dent. 2021; 22(4): 685-692.

[61] Lourenço Neto N, Marques NC, Fernandes AP, Hungaro Duarte MA, Abdo RC, Machado MA, et al. Clinical and radiographic evaluation of Portland cement added to radiopacifying agents in primary molar pulpotomies. Eur Arch Paediatr Dent. 2015; 16(5): 377-82.

[62] Sakai VT, Moretti AB, Oliveira TM, Fornetti AP, Santos CF, Machado MA, et al. Pulpotomy of human primary molars with MTA and Portland cement: a randomised controlled trial. Br Dent J. 2009; 207(3): E5; discussion 128-9.

[63] Maroto M, Barreiro S, Barbería E. Portland cement as pulp dressing agent in pulpotomy treatment of primary molars: a 12-month clinical study. Eur J Paediatr Dent. 2019; 20(1): 23-26.

[64] Petel R, Ziskind K, Bernfeld N, Suliman H, Fuks AB, Moskovitz M. A randomised controlled clinical trial comparing pure Portland cement and formocresol pulpotomies followed from 2 to 4 years. Eur Arch Paediatr Dent. 2021; 22(4): 547-552.

[65] Oliveira TM, Moretti ABS, Sakai VT, Lourenço Neto N, Santos CF, Machado MA, et al. Clinical, radiographic and histologic analysis of the effects of pulp capping materials used in pulpotomies of human primary teeth. Eur Arch Paediatr Dent. 2013; 14: 65-71.

[66] Ramanandvignesh P, Gyanendra K, Jatinder Kaur Goswami Mridula D. Clinical and radiographic evaluation of pulpotomy using MTA, Biodentine and Er,Cr:YSGG laser in primary teeth- A clinical study. Laser Ther. 2020; 29(1): 29-34.

[67] Çelik BN, Mutluay MS, Arıkan V, Sarı Ș. The evaluation of MTA and Biodentine as a pulpotomy materials for carious exposures in primary teeth. Clin Oral Investig. 2019; 23(2): 661-666.

[68] Rubanenko M, Petel R, Tickotsky N, Fayer I, Fuks AB, Moskovitz M. A randomized controlled clinical trial comparing tricalcium silicate and formocresol pulpotomies followed for two to four years. Pediatr Dent. 2019; 41(6): 446-450.

[69] Li TY, Chuang LC, Tsai AI. A retrospective study of sodium hypochlorite pulpotomies in primary molars. J Dent Sci. 2016; 11(3): 261-265.

[70] Rosenfeld EF, James GA, Burch BS. Vital pulp tissue response to sodium hypochlorite. J Endo. 1978; 5: 140-6.

[71] Hafez AA, Cox CF, Tarim B, Otsuki M, Akimoto N. An in vivo evaluation of hemorrhage control using sodium hypochlorite and direct capping with a one- or two-component adhesive system in exposed nonhuman primate pulps. Quintessence Int. 2002; 33(4): 261-72.

[72] Hafez AA, Kopel HM, Cox CF. Pulpotomy reconsidered: application of an adhesive system to pulpotomized permanent primate pulps. Quintessence Int. 2000; 31(8): 579-89.

[73] Vargas KG, Packham B, Lowman D. Preliminary evaluation of sodium hypochlorite for pulpotomies in primary molars. Pediatr Dent. 2006; 28(6): 511-7. 
[74] Al-Mutairi MA, Bawazir OA. Sodium hypochlorite versus Formocresol in primary molars pulpotomies: a randomized clinical trial. Eur J Paediatr Dent. 2013; 14(1): 33-6.

[75] Chauhan SP, Gupta M, Ahmed H, Tongya R, Sharma D, Chugh B. Evaluation and comparison between formocresol and sodium hypochlorite as pulpotomy medicament: A randomized study. $J$ Contemp Dent Pract. 2017; 18(11): 1029-1033.

[76] Nematollahi H, Sahebnasagh M, Parisay I. Comparison of electrosurgical pulpotomy with zinc oxide eugenol or zinc polycarboxylate cements sub-base. J Clin Pediatr Dent. 2011; 36(2): 133-7.

[77] Dean JA, Mack RB, Fulkerson BT, Sanders BJ. Comparison of electrosurgical and formocresol pulpotomy procedures in children. International Journal of Paediatric Dentistry. 2002; 12(3): 177-182.

[78] Ansari G, Safi Aghdam H, Taheri P, Ghazizadeh Ahsaie M. Laser pulpotomy-an effective alternative to conventional techniques-a systematic review of literature and meta-analysis. Lasers Med Sci. 2018; 33(8): 1621-1629.

[79] Odabaş ME, Bodur H, Bariş E, Demir C. Clinical, radiographic, and histopathologic evaluation of $\mathrm{Nd}$ :YAG laser pulpotomy on human primary teeth. J Endod. 2007; 33(4): 415-21.

[80] Saltzman B, Sigal M, Clokie C, Rukavina J, Titley K, Kulkarni GV. Assessment of a novel alternative to conventional formocresol-zinc oxide eugenol pulpotomy for the treatment of pulpally involved human primary teeth: diode laser-mineral trioxide aggregate pulpotomy. Int $J$ Paediatr Dent. 2005; 15(6): 437-47.

[81] Elliott RD, Roberts MW, Burkes J, Phillips C. Evaluation of the carbon dioxide laser on vital human primary pulp tissue. Pediatr Dent. 1999 ; 21(6): 327-31.

[82] Gutknecht N, Moritz A, Conrads G, Sievert T, Lampert F. Bactericidal effect of the Nd:YAG laser in in vitro root canals. J Clin Laser Med Surg. 1996; 14(2): 77-80

[83] Moskovitz M, Tickotsky N, Dassa M, Fux-Noy A, Shmueli A. et al. Zinc Oxide Zinc Sulfate versus Zinc Oxide Eugenol as Pulp Chamber Filling Materials in Primary Molar Pulpotomies. Children (Basel). 2021; 8(9): 776 .

[84] Hume WR. The pharmacologic and toxicological properties of zinc oxide-eugenol. J Am Dent Assoc. 1986; 113(5): 789-91.

[85] Chien MM, Setzer S, Cleaton-Jones P. How does zinc oxide-eugenol compare to ferric sulphate as a pulpotomy material? SADJ. 2001; 56(3): $130-5$

[86] Hui-Derksen EK, Chen CF, Majewski R, Tootla RG, Boynton JR. Retrospective record review: reinforced zinc oxide-eugenol pulpotomy: a retrospective study. Pediatr Dent. 2013; 35(1): 43-6.

[87] Gonzalez-Lara A, Ruiz-Rodriguez MS, Pierdant-Perez M, GarrochoRangel JA, Pozos-Guillen AJ. Zinc oxide-eugenol pulpotomy in primary teeth: A 24-month follow-up. J Clin Pediatr Dent. 2016; 40(2): 107-12.

[88] Dawood AE, Parashos P, Wong RHK, Reynolds EC, Manton DJ. Calcium silicate-based cements: composition, properties, and clinical applications. J Investig Clin Dent. 2017; 8(2).

[89] Utneja S, Nawal RR, Talwar S, Verma M. Current perspectives of bioceramic technology in endodontics: calcium enriched mixture cement - review of its composition, properties and applications. Restor Dent Endod. 2015; 40(1): 1-13.

[90] Gandolfi MG, Spagnuolo G, Siboni F, Procino A, Rivieccio V, Pelliccioni GA, et al. Calcium silicate/calcium phosphate biphasic cements for vital pulp therapy: chemical-physical properties and human pulp cells response. Clin Oral Investig. 2015; 19(8): 2075-89.

[91] Jose B, Ratnakumari N, Mohanty M, Varma HK, Komath M. Calcium phosphate cement as an alternative for formocresol in primary teeth pulpotomies. Indian J Dent Res. 2013; 24(4): 522.

[92] Kalaskar RR, Damle SG. Comparative evaluation of lyophilized freeze dried platelet derived preparation with calcium hydroxide as pulpotomy agents in primary molars. J Indian Soc Pedod Prev Dent. 2004; 22(1): 24-9.

[93] Devi Praja V, Muttath AL, Duraisamy V, Selvarajan NB, Suresh Kumar V, Baby John J. A clinical and radiographic comparison of platelet-rich fibrin and lyophilized platelet-derived preparation as pulpotomy agent in primary molars. J Pharm Bioallied Sci. 2020; 12(1): 155-160.

[94] Patidar S, Kalra N, Khatri A, Tyagi R. Clinical and radiographic comparison of platelet-rich fibrin and mineral trioxide aggregate as pulpotomy agents in primary molars. J Indian Soc Pedod Prev Dent. 2017; 35(4): 367-373.

[95] Al-Hezaimi K, Naghshbandi J, Alhuzaimi R, Alonizan F, AlQwizany I, Rotstein I. Regeneration of secondary dentin using recombinant human platelet-derived growth factor and MTA for pulp capping: a randomized controlled human clinical trial. Int $J$ Periodontics Restorative Dent. 2020; 40(4): 477-485.
[96] Al-Hezaimi K, Naghshbandi J, Alhuzaimi R, Alonaizan F, AlQwizany I, Rotstein I. Evaluation of recombinant human platelet-derived growth factor or enamel matrix derivative plus calcium hydroxide for pulp capping: a randomized controlled human clinical trial. Int $J$ Periodontics Restorative Dent. 2020; 40(5): 645-654.

[97] Salako N, Joseph B, Ritwik P, Salonen J, John P, Junaid TA. Comparison of bioactive glass, mineral trioxide aggregate, ferric sulfate, and formocresol as pulpotomy agents in rat molar. Dent Traumatol. 2003; 19(6): 314-20.

[98] Jones JR, Ehrenfried LM, Hench LL. Optimising bioactive glass scaffolds for bone tissue engineering. Biomaterials. 2006; 27: 964 973.

[99] Neeraja Govindaraj, Kinjal Shah Virani, Priya Subramaniam, Megha Gupta. Evaluation of bioactive glass and hydroxyapatite crystals as pulpotomy agents in primary molars: A clinical study. Contemp Pediatr Dent. 2020: 1(1): 42-51.

[100]Elhamouly Y, El Backly RM, Talaat DM, Omar SS, El Tantawi M, Dowidar KML. Tailored 70S30C Bioactive glass induces severe inflammation as pulpotomy agent in primary teeth: an interim analysis of a randomised controlled trial. Clin Oral Investig. 2021; 25(6): 3775 3787.

[101] Adlakha VK, Chandna P, Joshi J, Thomas A, Singh N. A comparative evaluation of hydroxyapatite crystals and glutaraldehyde as agents for pulpotomy in deciduous molars. Int J Clin Pediatr Dent. 2009; 2(1): $13-22$.

[102] Shayegan A, Atash R, Petein M, Abbeele AV. Nanohydroxyapatite used as a pulpotomy and direct pulp capping agent in primary pig teeth. J Dent Child (Chic). 2010; 77(2): 77-83.

[103]Fadavi S, Anderson AW, Punwani IC. Freeze-dried bone in pulpotomy procedures in monkey. J Pedod. 1989; 13(2): 108-22.

[104] Wang YH, Rutherford B, Upholt WB, Mina M. Effects of BMP-7 on mouse tooth mesenchyme and chick mandibular mesenchyme. Dev Dyn. 1999; 216: 320-335.

[105] da Silva LA, de Paula e Silva FW, Leonardo MR, Assed S. Pulpal and periapical response of dogs' teeth after pulpotomy and use of recombinant human bone morphogenetic protein-7 as a capping agent. J Dent Child (Chic). 2007; 74(2): 79-84.

[106] Wang HH, Sarmast ND, Shadmehr E, Angelov N, Shabahang S, Torabinejad M. Application of enamel matrix derivative (Emdogain) in endodontic therapy: A comprehensive literature review. J Endod. 2018; 44(7): 1066-1079

[107] Nakamura Y, Hammarström L, Matsumoto K, Lyngstadaas SP. The induction of reparative dentine by enamel proteins. Int Endod J. 2002; 35(5): 407-17.

[108]Darwish SS, Abd El Meguid SH, Wahba NA, Mohamed AA, Chrzanowski W, Abou Neel EA. Root maturation and dentin-pulp response to enamel matrix derivative in pulpotomized permanent teeth. J Tissue Eng. 2014; 5: 2041731414521707.

[109]Fuks AB, Jones PC, Michaeli Y, Bimstein E. Pulp response to collagen and glutaraldehyde in pulpotomized primary teeth of baboons. Pediatr Dent. 1991; 13(3): 142-50.

[110] Anandan V, Inbanathan J, Saket P, Krishnamoorthy V, Gandhi S, Chandrababu VK. Assessment of clinical and radiographic success rate of formocresol-based pulpotomy versus collagen-based pulpotomy: An in vivo Study. J Contemp Dent Pract. 2021; 22(6): 680-685.

[111]Kim CH, Bae JS, Kim IH, Song JS, Choi HJ, Kang CM. Prognostic factors for the survival of primary molars following pulpotomy with mineral trioxide aggregate: a retrospective cohort study. Clin Oral Investig. $2021 ; 25(4): 1797-1804$ 